Review article

\title{
Color vision and color choice behavior of the honey bee
}

\author{
W Backhaus
}

Institüt für Neurobiologie, Freie Universität Berlin, Königin-Luise-Str 28-30, 1000 Berlin 33, Germany

(Received 29 October 1992; accepted 22 April 1993)

Summary - A general introduction to color vision in honeybees has been presented. Documenting the current state of research in this field, the theory of color vision and color choice behavior of the honeybee has been reviewed. Several tests of the predictions of the theory for behavioral and electrophysiological experiments have been presented. The properties of color memory have been derived. A complete neuronal interpretation of the color theory has been given. The decision-making process has been discussed with respect to the fluctuations in the neuronal network. In specificallydesigned experiments, the information provided by the color vision system has been combined with the information from other perceptual systems in color choice behavior. Respective extensions of the color theory for the bee have been discussed.

Apis mellifera / honey bees / color vision / choice behavior / perception / psychophysics / electrophysiology

\section{INTRODUCTION}

Honey bees (Apis mellifera $\mathrm{L}$ ) collect the nectar and the pollen of flowers as food for their colony. When performing this task, honeybees show flower constancy; $i e$, as Aristotle already mentioned (Gohlke, 1951-1961), individual honeybees exclusively visit flowers of the same species as long as nectar is provided. However, honeybees are not specialized to forage on specific flower species. They are generalists, ie they are able to learn the color and other cues (eg odor and form) of all kinds of flowers. The color of the corolla is used by the bee as a cue for identifying flowers of the currently visited species from afar.
The odor cue can be used by the bee only to confirm that a given flower belongs to the correct species if the bee is close to the flower. Thus the better the bee is able to discriminate the colors of different flower species from their respective backgrounds, and from each other from a distance, the higher the intake of nectar and pollen for the bee colony.

How can such a small animal perform this sophisticated color discrimination and color identification task? This question can now broadly be answered in physiological and psychological terms on the basis of a complete color theory for the honeybee developed by the present author and which will be reviewed in this article. 
The generalistic foraging behavior of the bee (see above) permits color training experiments. Individual bees can be trained to visit color plates by rewarding them with sucrose solution. In tests, altenative color plates can be presented in addition to the known plate. During the unrewarded tests, which may last up to $4 \mathrm{~min}$, the experimental bee searches across the experimental arrangement for a reward. It visits the different color plates according to their similarity to the known plate. Thus the plates which appear most similar to the known plate to the bee are visited less often; plates which appear to be more different from the known plate are visited less often. The choices can easily be counted by the experimenter. Each test is followed by a training session in which the bee is fed again, thus reinforcing its prior training. The experimental bee takes the sucrose solution immediately to the hive then returns directly to the experiment within a few minutes with an empty stomach, looking highly motivated for the next reward.

Karl von Frisch (1914) was the first to demonstrate in behavioral experiments of this kind that bees possess a true color sense. He demonstrated that honeybees are able to distinguish a blue-colored cardboard from a series of cardboards which appeared grey to the human eye. Since this pioneering work, color vision in honeybees has been extensively investigated in more sophisticated experiments. Karl Daumer (1956), a student of Karl von Frisch, performed color training experiments with bees in which he systematically investigated which mixtures of 3 monochromatic lights appear indistinguishable to the bee. He showed that bees must be trichromats, ie that 3 different photoreceptor types (UV,B,G) contribute to the color vision system of the bee. Von Helversen (1972) measured discrimination of monochromatic lights in terms of a complete wavelength discrimination function. Wave- length discrimination is best around $400 \mathrm{~nm}$ and also $490 \mathrm{~nm}$. Menzel (1981) measured the thresholds for chromatic/ achromatic vision in color training experiments with achromatic light and monochromatic lights exclusively varied in intensity over 12 log-units which covers the entire range from dark to bright daylight.

Neuronal color coding was also investigated by intracellular recording techniques. Since the first recordings of Autrum and von Zwehl (1964), spectral sensitivities of the photoreceptors in honeybees have been repeatedly measured with increasing accuracy. Menzel et al (1986) measured the spectral sensitivity functions of the photoreceptors intracellularly with high accuracy with the help of a fast spectral scan method. This method allowed measurement of the entire spectral sensitivity function of a photoreceptor in 4-nm steps in the range of $300-696 \mathrm{~nm}$ within $16 \mathrm{~s}$. Since the receptor potential was kept (lightclamped) at low excitation values, the measurements were not disturbed by adaptation effects. These light clamp spectral sensitivity measurements are suitable for physiological simulation purposes. In addition, examples of spectral sensitivities of monopolar cells have been measured (Menzel, 1974; de Souza et al, 1992). Kien and Menzel (1977a,b) recorded 3 main types of color coding interneurons from the optic lobe: 1) broad band neurons which have a broad spectral sensitivity; 2) narrow band neurons which respond exclusively to specific monochromatic lights; and 3) color opponent coding neurons, which show excitation (increase of the resting spike frequency) to monochromatic lights of certain wavelength ranges and inhibition (decrease in resting spike frequency) to other wavelength ranges. Two subtypes of the latter neuron type were found: a) neurons which respond only to changes in light intensity (phasic neurons); or b) neurons whose response to a steady light intensity 
is sustained (tonic neurons). The neurons most likely to be essential for color vision were the tonic color opponent neurons, and they were most extensively studied. Only 2 different types of such opponent coding neurons were found (see below).

Although the brain of the honeybee is much simpler than the human brain it nevertheless possesses ca 850000 neurons, half of which are visual (Hertel and $\mathrm{Ma}$ ronde, 1987). The color vision system of the bee thus cannot be understood from electrophysiological and neuroanatomical studies alone. Nevertheless, it was suspected by the author that the representation of the world in the bee brain follows a quite simple logic, comparable to that in humans, and thus might be structurally similar to our own. So the author conceived the idea to apply theoretical methods from psychology, especially psychophysics, to the results of specially designed behavioral experiments with honeybees, and to design relatively simple but nevertheless physiologically adequate models of the neuronal color coding system of the bee. This approach bridged the gap between electrophysiology and behavioral biology. The result was a comprehensive theory of color vision and color choice behavior of the honeybee which has withstood rigorous testing. This theory will be developed step by step in the following chapters. Since the color theory for the bee was derived using the methods of human psychophysics, a short introduction to perceptual psychology is given in the next section for non-specialists.

\section{Human psychophysics}

Human perception represents the stimuli of the outer world internally in terms of qualitatively different perceptual attributes. The number of attributes or perceptual dimensions depends on the sensory system (mo- dality). In the case of human color vision, the color stimuli are represented internally as color sensations (color) which consist of 6 unique (elementary) color sensations: blue-, yellow-, red-, green-, black- and whiteness (Hering, 1905) in different proportions which also constitute the 3 perceptual attributes, hue, saturation (the opposite of whiteness), and brightness (eg Wyszecki and Stiles, 1982). Since the perceptual attributes differ qualitatively from each other, they will never be confused. Two different stimuli which affect the same modality (eg color vision) are distinguishable due to differences in the quantities of the perceptual attributes. Psychophysical investigations have shown that the extent of individual (one-dimensional) perceptual attributes is adequately described by linear scales, ie the quantity of a perceptual attribute is well represented by certain values (numbers) on the respective scales. Since the attributes are qualitatively different from each other, a mathematical description of the structure of perception is obtained by combining the scales orthogonally to each other in order to build the basis for a metric space. The mathematical concept of metric spaces turned out to be very useful for a more detailed determination of the structure of perception. In stimulus discrimination experiments, for example, the total subjective difference between 2 stimuli can be easily judged. The subject is then asked whether a stimulus is different from a standard stimulus or not. In another type of experiment (similarity experiment), the person is asked which one of 2 test stimuli is more similar to a third (standard) stimulus. Analysis of the results of both types of experiments showed that the total subjective difference between 2 stimuli can simply be derived by a combination rule from the differences in the amounts of the specific attributes. In the case of human color vision, for example, this rule is identical to the theorem of Pythagoras (Eu- 
clidean metric). That is, the total color difference between 2 color stimuli is just calculated as the square root of the sum of the squared differences in the values representing the stimuli on the separate scales (eg Sixtl, 1982).

\section{The psychological concept of perceptual spaces}

More mathematically speaking, the structure of perception is well represented by metric spaces (perceptual spaces). These spaces are spanned by the orthogonally arranged scales, also called the dimensions of the perceptual space. Psychophysicists have found that perception in humans is in general adequately described by perceptual spaces possessing the general class of Minkowski metrics (eg Ahrens, 1974). The subjective difference $d$ between 2 stimuli $S$ is derived from the differences in the respective scale values $X$, where $D$ is the number of scales (dimensions) and $m$ is the Minkowski parameter:

$$
d_{12}=d\left(S_{1}, S_{2}\right)=\left(\sum_{i=1}^{D}\left|X_{i 1}-X_{R 2}\right|^{m}\right)^{1 / m}
$$

Minkowski metrics include as special cases the Euclidean metric ( $m=2$, shortest line, ie straight line in space), the cityblock metric ( $m=1$, eg length of a walking path in a city with an equally spaced rectangular network of streets as in Manhattan, New York) and the dominance metric ( $m->\infty$, only the greatest of the differences on the scales contributes to the total difference between 2 stimuli $S$ ).

\section{Scaling methods}

Multidimensional scaling analysis (Torgerson, 1958; Kruskal, 1964a,b) permits the determination of the number of dimensions and the metric of a perceptual space. For each parameter combination for the number of dimensions $D$ and the Minkowski parameter $m$, the scale values of the stimuli are varied by special numerical procedures. The procedure determines the scale values which allow the best possible reproduction of the measured choice percentages. The lowest number of dimensions $D$ which gives an acceptable fit and the Minkowski parameter $m$, which gives the best fit for this number of dimensions, determine the perceptual space.

\section{THE PERCEPTUAL COLOR SPACE OF THE HONEYBEE}

The scaling methods for human perception (see above) were applied by the author to the choice percentages of honeybees measured in color similarity experiments. This does not mean that bees are necessarily supposed to possess conscious color sensations. As becomes obvious from the concept of perceptual color spaces (see above), this only supposes that color perception in bees is structurally comparable to color perception in humans. The results of the multidimensional scaling analysis showed that this supposition holds for the honeybee. In a first step, the author showed by statistical analysis (Monte-Carlo simulation) of measured choice percentages with respect to measured error bars that the choices obtained from the bee are accurate enough for MDS analysis (Backhaus and Menzel, 1984). On the basis of this result, the author suggested color similarity experiments specifically designed for MDS analysis of measured choice percentages so as to determine the perceptual color space of the bee. According to the method of triads (Torgerson, 1958), the measurements (a sketch of the experimental arrangement is shown in figure 1) were per- 


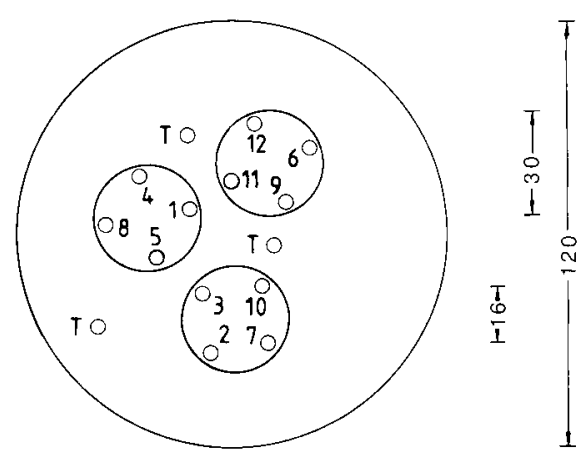

Fig 1. Sketch of the vertical arrangement for the multiple choice experiments performed for multidimensional scaling analysis for determining the subjective color space of the bee (from Backhaus et al, 1987). The experiments were performed outdoors with free-flying bees. The color stimuli presented in the tests (indicated by numbers) were cardboards and glass-filters covered with UV-transparent Plexiglass. The arrangement was illuminated by northern sky light (no direct sunlight). During training, the rewarded color signal T was presented at 3 different places outside the 3 groups of 4 color signals. During the tests, these stimuli were covered with a sheet of the same grey as the background.

formed by training individual bees to one out of 12 color stimuli. In the tests, all 12 stimuli were presented and the choices were counted. For MDS analysis, each of the 12 stimuli was trained, and subsequently the 12 stimuli were tested simultaneously (Backhaus et al, 1987). The author performed a multidimensional scaling (MDS) analysis of the measured choice percentages (Backhaus et al, 1987). The color space of the bee turned out in this analysis to be 2-dimensional with a cityblock metric. In addition, the scale values of the 12 stimuli were determined in addi- tion. The 2 dimensions were shown to code exclusively for chromaticness (the 2dimensional aspect of color which is different from brightness). The color space of the bee thus possesses 1 dimension less than the color space in humans (see above). This is because bees do not use a brightness system at all in the context of feeding and at the hive entrance (see also below) although they possess a brightness system as shown in the context of natural phototaxis (Labhart, 1974; Menzel and Greggers, 1985).

\section{NEURONAL INTERPRETATION OF THE COLOR SPACE}

Are the psychophysical scales of the color space only abstract numbers or do they have a physiological meaning? Are they processed somewhere in the bee brain, even perhaps coded in specific neurons? In order to answer these questions, the author constructed a physiological hypothesis taking into consideration the electrophysiological results on the color vision system of the bee and other insects. This hypothesis consists of 2 parts, namely the physiological description of the photoreceptors (PR model) and the color opponent coding (COC) model. The latter is a linear network with the photoreceptor potentials as input.

\section{The physiological photoreceptor (PR) model}

The light reflected from a color plate is simply calculated as the product of the spectral reflectance $r(\lambda)$ and the intensity distribution of the illuminating light $I_{d}(\lambda)$ (measured in number of photons $/ \mathrm{s} / \mathrm{cm}^{2}$ ). The relative photon flux which actually enters an ommatidium of the compound eyes of the bee is partially absorbed in 3 types 
of photoreceptor cells with differing spectral sensitivities. The photoreceptor spectral types are denoted by the index $i(i=1-$ 3) and are also denoted by $u, b, g$ indicating that the maxima of the respective spectral sensitivity functions possess maxima in the UV, blue or green region (for best estimate functions see Backhaus, 1991; Menzel and Backhaus, 1991; fig 2). The light which is actually absorbed in a specific photoreceptor type depends on the adaptation state of the cell and thus is called the relative (with respect to the adaptation state) absorbed photon flux. The relative absorbed photon flux $P$ is calculated from the photon flux I and the spectral sensitivity $s$ of the photoreceptors. The factor $R$ (range sensitivity, Laughlin, 1981) describes the adaptation state of the photoreceptor.

$$
P_{i}=R_{i} \int_{300}^{700} I(\lambda) s_{i}(\lambda) d \lambda, I(\lambda)=I_{d}(\lambda), i=1-3[2]
$$

The absorbed relative photon flux $P$ is transduced into the relative membrane potentials $V$ respective into the relative (to

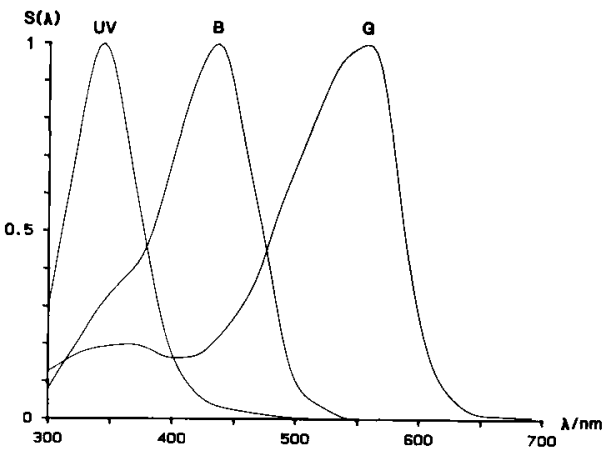

Fig 2. Spectral sensitivity functions $s(\lambda)$ of the 3 photoreceptor types (UV,B,G) in the honeybee compound eye (best estimate functions, from Backhaus, 1991). All the weighting factors in the color theory were determined with respect to these functions. the maximum value) cell excitations $E$ ( $\mathrm{Li}$ petz, 1971):

$$
E=V N_{\max }=P^{n /\left(P^{n}+1\right)}
$$

The exponent is assumed to be $n=1$ for dark and light adaptation. The adaptation mechanism which controls the range sensitivity $R$, is assumed in all 3 receptor cell types to give half maximal response $(P=1 \rightarrow E=0.5)$ when exposed for more than a few seconds to a background light. With these assumptions, the range sensitivities $A$ in the PR model for adaptation to light intensity $l_{\text {ad }}$ can be determined as:

$$
R_{i}=1 / \int_{700}^{300} l_{a d}(k) s_{j}(k) d k
$$

For adaptation to daylight (normlight function D65, Henderson, 1970), the range sensitivities are calculated to stand in the relations:

$$
R^{u}: R^{b}: R^{g}=6.4: 1.7: 1
$$

It has been shown by simulation of electrophysiological and behavioral experiments with dark adapted bees that the same relations hold for dark adaptation (Backhaus, 1991, 1992; see also below).

\section{The color opponent coding (COC) model}

The photoreceptors feed into the first order interneurons, the monopolar cells which mainly amplify the signals from the photoreceptors. The monopolar cells are assumed to feed into color opponent coding neurons (see above). The color opponent coding (COC) model in conjunction with the PR model (fig 3) describes coding of color information from the photoreceptor cell excitations $E$, via linearly amplifying 


\section{The Theory of Color Vision and Color Choice Behavior of the Bee}

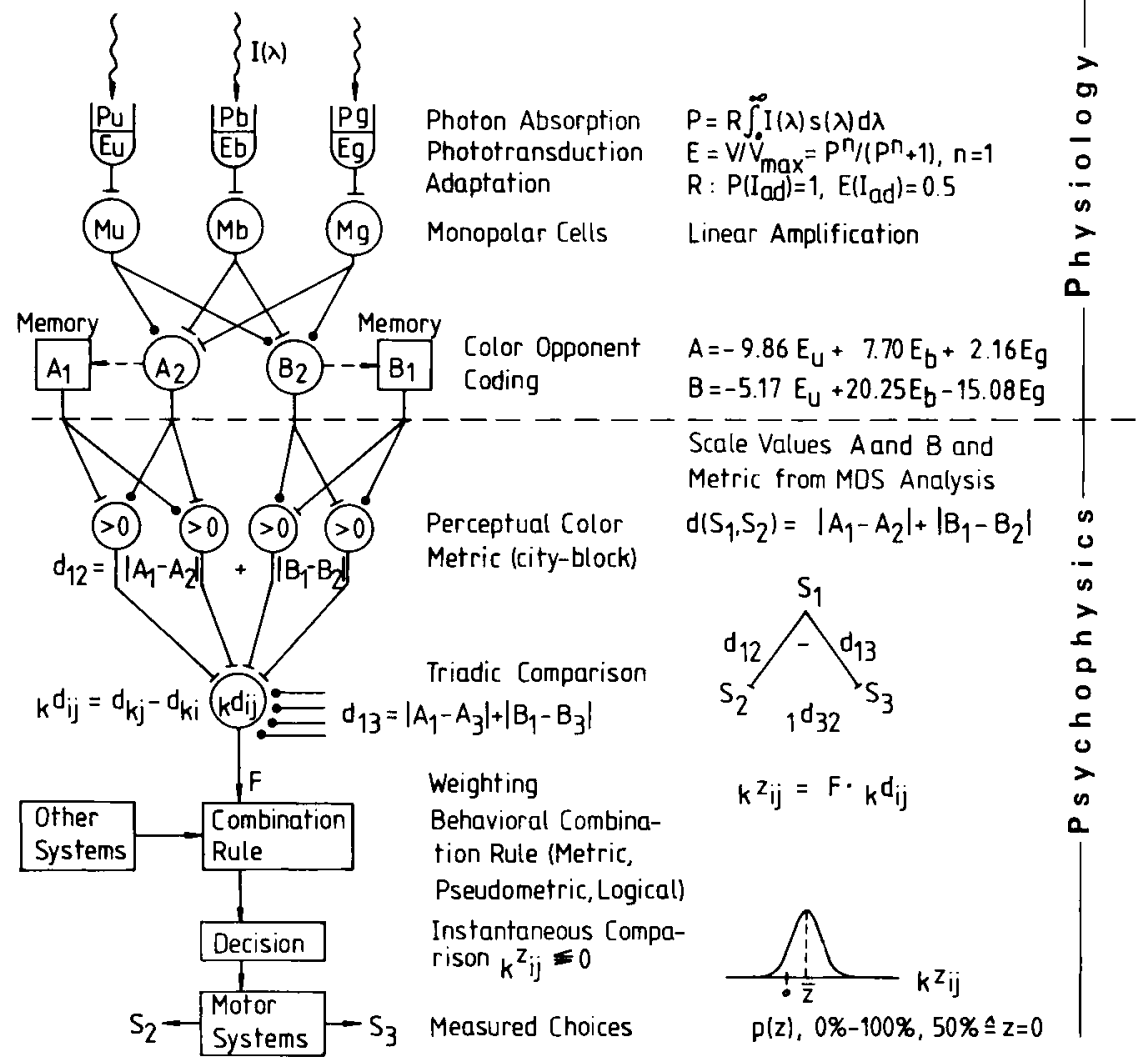

Fig 3. The theory of color vision and color choice behavior of the bee. The upper part (above dashed line) is related to the physiology of the color vision system. The lower part is related to psychophysics of color vision. The complete mathematical description (right side) and the neuronal interpretation of the theory (left side) is presented. $I(\lambda)$ : light intensity; $u, b, g$ : photoreceptor cell types; $R$ : range sensitivities; $s(\lambda)$ : spectral sensitivity; $P$. absorbed photon flux; $E$ : cell excitation; $V$ : cell potential; $M$ : monopolar cell; $A, B$ : excitations of color opponent coding neurons (circles: interneurons, boxes memories); $d_{k i}$ : color difference of 2 stimuli $S_{k}$ and $S_{i} ;{ }_{k} d_{i j}$ : judgment values of stimuli $S_{i}$ and $S_{j}$ with stimulus $S_{k}$; $F$ : experiment type dependent scaling factor; ${ }_{k} d_{i j}$ : weighted judgment values; $p(z)$ : inverse $z-$ transformation to choice percentages $p$. Also the psychophysical part of the theory (lower part, right side) allows for a complete neuronal interpretation. All the neurons in the small network possess simple (linear) properties: >0: 2 antagonistic coding neuron types with resting frequency zero, exclusively coding for positive differences in the synaptical inputs. Excitatory (hyphen) and inhibitory (dots) synapses appear interchanged in both neuron types. So the sum of the ouput of this pair of neurons represents the absolute value of the difference in the (memorized) excitations $A$ or $B$. ${ }_{k} d_{i j}$ : a judgment value neuron which realizes the city-block metric by adding the results from the pairs of $(>0)$-neurons. If the training stimulus is not shown (but stored as $A$ and $B$ values in memory) and 2 alternatives are presented in the tests, this neuron gets an inhibitory input from the additional $(>0)$-neurons, providing the necessary information about the additional color difference. The output of this neuron is weighted by an experiment type-dependent factor $F$. In mixed contexts, in which the behavior is not exclusively related to color vision, other perceptual systems can contribute to the choice behavior as well which is described by a behavioral combination rule (metric, pseudometric or logical relation) (see text). The decision process is related to the actual sign of weighted judgments values. The decision process is well described according to Thurstone's (1927) law of comparative judgment Case V (see text), describing the judgment values ${ }_{k} d_{i j}$ as fluctuating according to a Gaussian function with a constant standard deviation. The decision process is instantaneous, ie the decisions are made according to the actual sign of the judgment values ${ }_{k} d_{i j}$ at the moment of decision. If ${ }_{k} d_{i j}$ is $>0$, for example, stimulus $S_{3}$ is chosen; if ${ }_{k} d_{i j}$ is $<0$, stimulus $S_{2}$ is chosen. 
tonic monopolar cells, by 2 linear opponent coding neuron types $A$ and $B$ (Backhaus, 1987, 1988a, 1991):

$$
\begin{aligned}
& A=-9.86 E_{\mathrm{u}}+7.70 E_{\mathrm{b}}+2.16 E_{\mathrm{g}} \\
& B=-5.17 E_{\mathrm{u}}+20.25 E_{\mathrm{b}}-15.08 E_{\mathrm{g}}
\end{aligned}
$$

The 6 factors were determined by a least-squares fit of the excitations $A$ and $B$
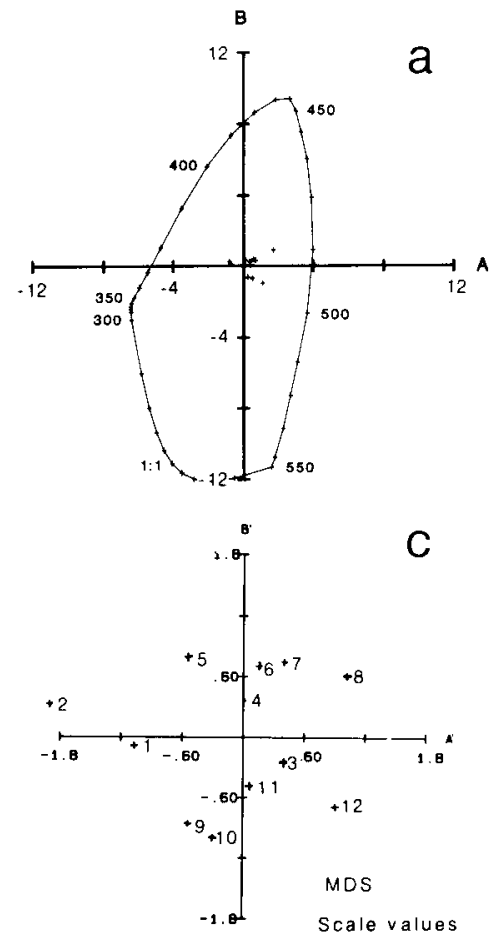

calculated from eq [2-7] for the 12 spectral intensity distributions $l(k)$ of the 12 color stimuli used in the color similarity experiments (see above) to the 12 corresponding scale values $A^{\prime}$ and $B^{\prime}$ derived by MDS analysis (fig 4):

$$
\sum_{i=1}^{12}\left(A_{i}-A_{i}\right)^{2}=\min , \text { analog for } B
$$

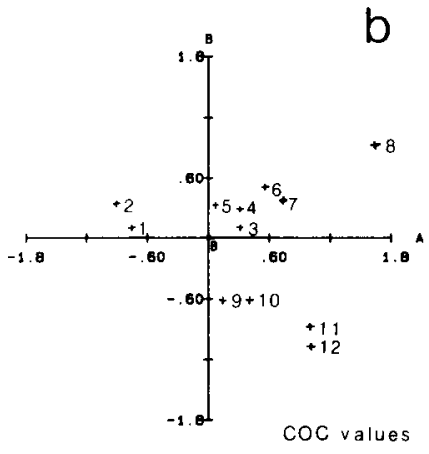

Fig 4. Comparison of the scale values derived from multidimensional scaling (MDS) analysis of the choice percentages measured in a multiple choice experiment (fig 1 and text) and the scale values derived from the PR- and the COC-model for the 12 stimuli used (from Backhaus, 1991). The COC diagram (a) shows the excitation values of the 12 color stimuli used in the multiple choice experiments mentioned in the text and, for orientation, the curve of monochromatic lights which give the same total relative photon flux absorbed in the photoreceptors as the average adaptation light in the experiments. (b) shows the magnified center part of (a). The scale values (c) derived by multidimensional scaling (MDS) analysis of the choice percentages measured in the experiments are shown for a comparison. The scale values $A, A^{\prime}$ respectively $B$ and $B^{\prime}$ were assumed to be identical; the deviations are due to experimental errors (eg fluctuations in the illumination of the outdoor experiments). The parameters of the COC model were determined by a least-squares fit of the scale values $A$ with respect to $A^{\prime}$ and of $B$ with respect to $B^{\prime}$ (see text). 
Neither the magnitude nor the sign of the 6 weighting factors (numbers in eq [6, 7] were preset. Nevertheless, the signs of these factors were determined to be identical, and the magnitudes are very close to those of the 2 types of tonic color opponent coding neurons (Type $A$ : $U V^{-} B^{+} G^{+}$, Type $B$ : $U V^{-} B^{+} G^{-}$) exclusively found by intracellular recording from the optic lobes of the bee brain (Kien and Menzel, 1977b). A simulation of the electrophysiological measurements of the spectral sensitivity of the color opponent coding neurons $A$ and $B$ shows a close correspondence to the measured spectral sensitivities (see fig 5). This shows that the MDS-scales are not merely mathematical constructs, but are identical to the excitations of the 2 types of color opponent coding cells in the bee's brain.

\section{THE PSYCHOPHYSICAL (MDS) MODEL}

Since the MDS scale values were shown to be identical to the excitations of the color opponent coding neurons $A$ and $B$, the choice percentages can be calculated for any stimulus whose spectral intensity distribution is known. All that is necessary is first to calculate the excitations $A$ and $B$ according to the COC model in conjuction with the PR model (eq [2-7]) and then to continue with the calculations according to the psychophysical (MDS) model used in the MDS analysis. With this psychophysical extension to the physiological hypothesis, the color difference $d$ between 2 stimuli $S_{1}$ and $S_{2}$ can be derived directly via the city-block metric from the excitations $A$ and $B$ in the 2 types of color opponent coding neurons instead of scale values obtained by MDS analysis:

$$
d_{12}=d\left(S_{1}, S_{2}\right)=\left|A_{1}-A_{2}\right|+\left|B_{1}-B_{2}\right|
$$

Color differences can be directly measured in color discrimination experiments. In such experiments, the bee is 1 color stimulus and in the tests this stimulus is presented simultaneously with an alternative color stimulus. In color similarity experiments, the trained stimulus $S_{k}$ is not presented in the tests. According to the method of triads (Torgerson, 1958), only the 2 alternatives $S_{1}$ and $S_{2}$ are shown, both of which are different from the trained stimulus. The $2 \mathrm{col}-$ or differences $d_{12}=d\left(S_{1}, S_{2}\right)$ and $d=d$ $\left(S_{1} S_{2}\right)$ between the trained color stimulus $S_{1}$ and the 2 alternatives $S_{2}$ and $S_{3}$ are subtracted from each other in order to give the judgment values ${ }_{1} d_{23}$ which reads in general notation:

$$
{ }_{k} d_{i j}=d_{k j}-d_{k i}
$$

In the case of color difference experiments $\left(d_{k j}=0\right)$ the judgment value ${ }_{k} d_{i j}$ is simply the color difference $d_{k i}$ between the training stimulus $S_{k}$ and the alternative $S_{i}$.

\section{THE MODEL OF COLOR CHOICE BEHAVIOR (CCB)}

In the model of color choice behavior (CCB) the judgment values ${ }_{k} d_{i j}$ are scaled by an experiment-type-dependent factor $F$ in order to give so-called $z$-values (Backhaus, 1992):

$$
k^{z_{i j}}=F_{k} d_{i j}
$$

$F$ is a global scaling factor which gauges the judgment values with respect to the maximum choice percentage obtained $(87-100 \%)$ in the respective experiment (see below). From $z$-values, the choice probabilities $p$ are directly derived by inverse $z$-(probability) transformation (Torgerson, 1958). This can either be performed by looking up the respective $p(z)$ values in a table (eg Torgerson, 1958). Or the transformation can be calculated in a 


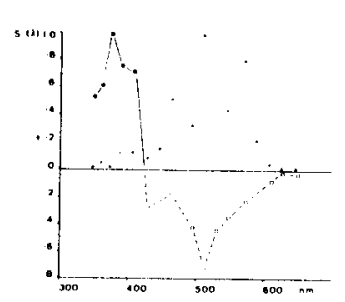

a

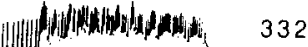

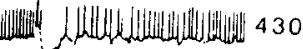

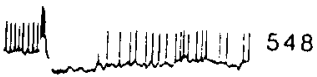

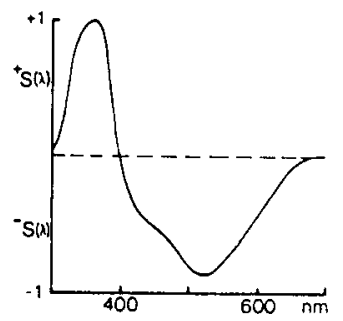

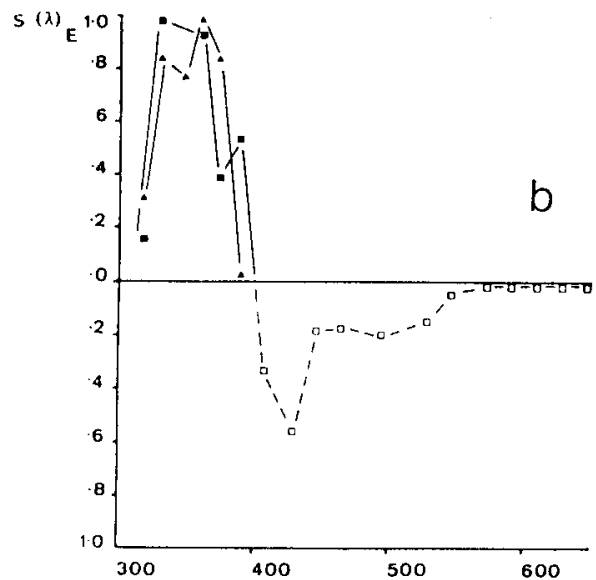

C
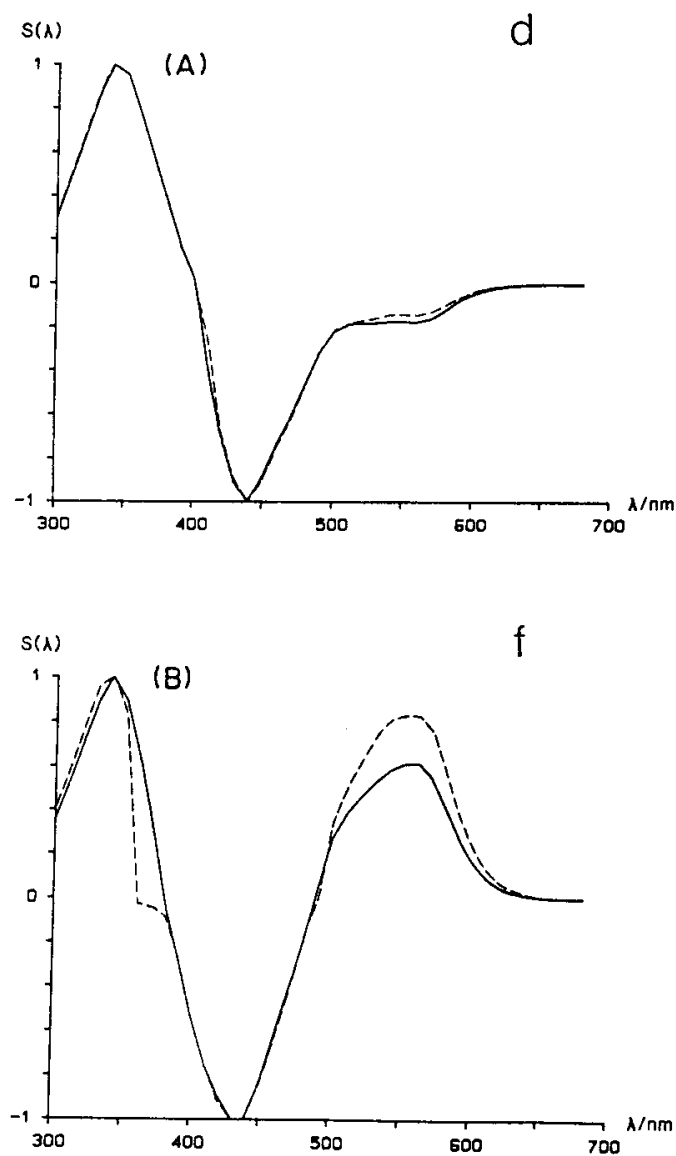
good approximation (after Zielinski, 1978) by:

$$
k_{k i j}=1 /\left\{1+\exp \left[-(8 / \pi)^{1 / 2} k^{z_{i j}}\right\}, 0<{ }_{k} p_{i j}<1[12]\right.
$$

This allows us to predict with eq [2-12] measurable color choice percentages $(p \mathrm{x}$ $100 \%$ ) exclusively from the spectral intensity distribution of the stimuli with the experiment-type-dependent factor $F$ as the only open parameter in the entire theory. It is obvious from eq $[11,12]$ that this factor is just a scaling factor and has no influence on the general form of the choicepercentage functions.

It turned out (see examples below) that the results are sufficiently accurate, if the spectral intensity distributions (spectral intensity distribution times reflectance of the stimuli) are measured in 4-nm steps and if the integrals are approximated by the sum of the results of the multiplications performed for the 4-nm intervals. In the case of multiple color discrimination experiments, in the tests several alternatives are presented in addition to the trained stimulus. In the case of multiple color similarity experiments, many alternatives which all differ from the training stimulus are shown in the tests. Dual choice proportions, as measured in color discrimination or triadic color similarity experiments, can also be obtained from the choice frequencies measured in the corresponding type of multiple choice experiment. Since bees chose the color stimuli statistically independently (von Helversen, 1972; Dittrich, 1992), the choice probabilities for each 2 color stimuli can be directly calculated from the choice frequencies obtained in multiple choice experiments (Guilford, 1937; Backhaus et al, 1987):

$$
{ }_{k} p_{i j}={ }_{k} f_{i} /\left({ }_{k} f_{i}+{ }_{k} f_{j}\right)
$$

Multiple choice experiments allow us to obtain almost the same information as dual choice experiments but in much less time. The complete measurement of the similarity relations between 12 stimuli would need 660 dual choice experiments, whereas only 12 multiple choice experiments have to be performed to obtain all the dual choice percentages. The only disadvantage of the latter method is that not all of the derived choice percentages are statisti-

Fig 5. Comparison of the measured spectral sensitivities $s(\lambda)$ of the 2 types of color opponent coding neurons exclusively found (a,b,c: type $A: U^{-} B^{+} G^{+}$and e: type $\left.B: U V^{-} B^{+} C^{-}\right)$) with the spectral sensitivities for these neurons calculated from the COC-model (d: type $A$ and $f$ : type $B$ ). The functions a) and b) are 2 examples of type $A$ neurons (from Kien and Menzel, 1977b). The sustained excitatory (filled squares) and the inhibitory (open squares) response and the ON-response (triangles) are shown. The functions (c,e) (from Menzel and Backhaus, 1989) were generalized from several examples of each neuron type; c) corresponds to type $A$ neurons and e) corresponds to type $B$ neurons). The traces (c,e) give examples for single cell recordings of each cell type. Firstly, response - intensity curves were derived from the COC model. The spectral sensitivities (d,f, from Backhaus, 1991) were then derived from these functions for 2 extreme response criteria $(6.3 \%$ of the maximal/minimal response (--) and $1 \%$ of the maximal/minimal response $(-))$. The shape of the functions is only slightly dependent on the threshold criterion. The comparison of the measured curves $(a, b, c)$ and e) with the theoretical curves $d$ ) and f), respectively, shows a very good agreement in form as well as in the characteristic points (minima, maxima, and zero-crossings). The comparison shows in addition that the variability of the recordings of type $A$ neurons was higher (compare in a,b,c the relative heights and the positions of the minimum of the inhibitory part on the wavelength scale) than the variability in the recordings of the type $B$ neurons (no broadening of the inhibitory or excitatory parts in e). 
cally independent, because the same choice frequencies are used several times in different combinations. This prevents the application of tests of significance to the whole set of derived dual choice percentages. However, the predicted and the measured choice percentages can be pairwise compared with each other and tested for significant differences.

\section{Determination of the experiment-type- dependent scaling factor}

The experiment-type-dependent scaling factor $F$, the only open parameter in the entire theory, can be determined for best fit of the predicted to the measured choice percentages. For this purpose it is convenient to calculate first the regression line (eg Sachs, 1976) between the predicted judgment values $d$ (eq [10]) and the measured choice percentages $p$ transformed by the inverse of eq [12] with $F=1$ (ztransformation) given here for the reader's convenience when applying the color theory to measured data:

$$
k_{k} z_{i j}=\ln \left({ }_{k} p_{i j} /\left(1-{ }_{k} p_{i j}\right) /\left[(8 / \pi)^{1 / 2}\right], 0<{ }_{k} p_{i j}<1[14]\right.
$$

The experiment type-dependent factor $F$ can be read off directly as the steepness parameter determined by linear regression analysis of the measured $z(p)$-values (eq [14]) with respect to the predicted $d$-values (eq [10]). The multiplication of the predicted $\alpha$-values by this factor $F$ gives the predicted $z$-values (eq [11]). It has to be pointed out that scaling of the $d$-values by $F$ does not change the correlation coefficient between the predicted and the measured values. However, the steepness parameter becomes unity indicating the best fit between the predicted and the measured choice percentages is obtained and thus the proper factor $F$ is determined.

\section{SIMULATIONS OF BEHAVIORAL AND ELECTROPHYSIOLOGICAL EXPERIMENTS}

The hypotheses of color vision and color choice behavior of the bee presented allow us to calculate predictions for behavioral as well as for electrophysiological experiments. This has been done for several critical experiments in order to test the hypotheses.

\section{The Bezold-Brücke effect exists in the bee as predicted}

Intensity differences do not explicity contribute to the total color difference (eq [29]. However, color difference depends indirectly on intensity, because the nonlinearity of the photoreceptors does not allow for a coding of chromaticness totally independent of changes in intensity. Thus, it was shown by the author that intensitydependent color shifts (the Bezold-Brücke effect) must also occur in the color vision system of the honeybee. The analysis showed that the 3 gain values of eq [6] and eq [7] each add up to zero. This finding implies that if the phototransduction process followed a logarithmic function, the color vision mechanisms would code chromaticness totally independently of intensity changes (Backhaus, 1991). This finding might be of special interest from the ecological and evolutionary point of view since the phototransduction process is indeed well approximated by a logarithmic function over $\approx 1$ log-unit about the adaptation intensity. If the bee is looking at natural scenary (eg flowers on grass) the BezoldBrücke effect is indeed minimal. Since the transduction function does not exactly follow a logarithmic function (eq [2]), the Bezold-Brücke effect must be greatest where the deviations are greatest, namely at very high and very low light intensities (Back- 
haus, 1991), ie the more unnatural the visual task. The magnitude and the course of the Bezold-Brücke color shifts with respect to changes in light intensity is very sensitive to the values of the weighting factors of the color opponent coding (COC) system. Thus the comparison of the predictions for the Bezold-Brücke effect for the bee (Backhaus, 1991) with experimental results are the most critical test for the existence of color opponent coding in bees.

Evidence that the Bezold-Brücke effect does indeed exist in bees was provided by theoretical investigations (Backhaus, 1992) of the results of an experiment (Menzel, 1981) which was performed much earlier for completely different purposes, namely for the determination of the behavioral thresholds of achromatic and chromatic vision. In these experiments, individual bees were trained to turn to one side in a Tmaze if they saw a white light at the decision point and to turn to the other side if they saw a monochromatic light. In the tests, the monochromatic light was shown at different intensities. In figure 6 the choice percentages of the bee for the side for the learned color are drawn over the intensity of the training monochromatic light present at the decision point during the tests. At very low intensities, below the absolute threshold of the photoreceptors, the bee does not see any light at all (see below) and thus walks randomly in the Tmaze (50\%: 50\%). At low intensities (1 log unit above threshold) the bee's choices indicate that the monochromatic light appears achromatic to the bee. At medium intensities ( 3 log units above threshold), the bee shows that the monchromatic light appears chromatic as during training. At higher intensities ( $>5 \mathrm{log}$ units above threshold), the monochromatic light appears once again to be achromatic to the bee. Figure 6 shows a comparison of the predictions (stars and dots) for the BezoldBrücke effect with the measured results (dashed lines, circles). In all 3 cases (413, 440 and $533 \mathrm{~nm}$ ) the fit is striking.

In Menzel's (1981) experiments, the bees discriminate a trained monochromatic light of a certain wavelength from an alternative of the same wavelength at different intensities. The striking fit of the predicted to the measured choice percentages conclusively shows that honeybees do not use a brightness system for intensity discrimination experiments even where the intensity range covers the entire physiologically relevant range from dark $(\log (l)=0$, no measurable effect of light) to 12 relative log-intensity units which compares with bright daylight. This result has been recently confirmed by a simulation (Brandt et al, 1993) of a behavioral experiment of von Helversen (1972) in which he determined the threshold sensitivity function (313 $666 \mathrm{~nm}$ ) covering almost the entire wavelength range visible to the bee over an intensity range comparable with that tested in Menzel's (1981) experiment.

These results clearly demonstrate that in general care must be taken if sensory systems are postulated to exist in an organism for operational reasons alone. The reactions of an organism to light intensity differences do not demonstrate conclusively that a brightness system is involved in light discrimination. The reaction might be due solely to intensity-dependent chromaticness changes (Bezold-Brücke effect) as is the case in the honeybee.

\section{Additional tests}

Several further behavioral and electrophysiological experiments were simulated. The scaling factor $F$ was determined for each experiment type (see above). All other parameters had the constant values as described above (eq [2-13]; fig 3). The results of the following behavioral and electrophysiological experiments were quanti- 

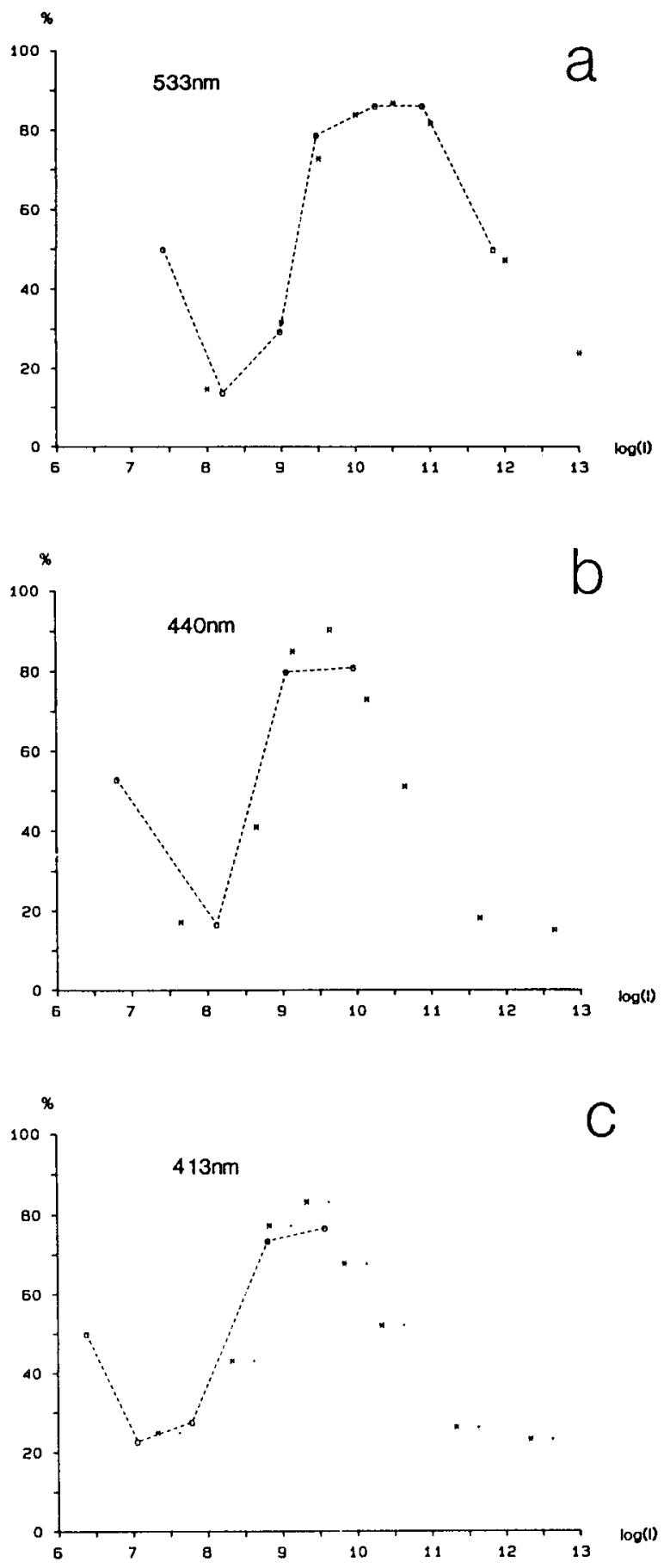

Fig 6. The Bezold-Brücke effect in the color vision system of the bee. In Menzel's (1981) color training experiments, individual bees were training to turn to one side in a T-maze when they saw monochromatic light presented from below at the decision point and to turn to the other side when they saw white light. The choice percentages were measured for the trained monochromatic light shown at different intensities at the decision point. Abscissa: relative light intensity in $\log$ units $(\log (1)$ : dark). Ordinate: choice percentages for the side the bee was trained to turn when monochromatic light is seen. The predictions ( ${ }^{*}$, dots) from the color theory (see text) for the Bezold-Brücke effect at the 3 wavelengths and at the respective intensities which were used in the experiments and the results of these experiments (circles, dashed lines; from Backhaus, 1992) are shown. a) The difference between the 2 color differences from the trained white and monochromatic light of $533 \mathrm{~nm}$ with respect to the tested monochromatic lights of $533 \mathrm{~nm}$ of different intensities were calculated (see text). The obtained judgment values were scaled by a constant experimenttype-dependent factor $F$ and $z$-transformed into choice percentages (stars). The factor $F$ was determined for best fit to the measured data (circles). The predicted percentages were shifted by eye on the $\log (l)$ scale without changing the relative intensities for best fit. b) A comparison of the predicted (stars) and the measured choice percentages for $440 \mathrm{~nm}$. The same factor and the same intensity scale as for 533 $\mathrm{nm}$ was used. c) A comparison of the predicted and the measured choice percentages for 413 $\mathrm{nm}$. The same factor as for $533 \mathrm{~nm}$ and the same intensity scale as for $533 \mathrm{~nm}$ was used. The predicted (dots) and measured results (circles) again agree very well. A small additional shift of $-0.3 \log$ units appears to give the best fit (stars) to the experimental data. This comparison demonstrates the predictive power of the color theory as well as the high accuracy of the experimental data obtained in color choice experiments with bees. 
tatively predicted and tested by comparison with the respective experimental data. All the predictions were confirmed by the experimental results given below. Thus the hypotheses of the author on color vision and color choice behavior of the bee achieved the status of a theory:

Behavior: 1) color discrimination and color similarity with respect to the training stimuli in dual and multiple choice experiments (Backhaus et al, 1987; Dittrich and Backhaus, 1991); 2) Bezold-Brücke color shifts (quantitatively predicted by Backhaus (1991) shown to exist by a comparison of the results of Menzel's (1981) experiments with the results of a simulation of these experiments by Backhaus (1992)); 3) the wavelength-discrimination function (comparison of the results of von Helversen's (1972) experiments with the results of a simulation of these experiments (Backhaus, 1991); 4) the threshold spectral sensitivity function (measured by von Helversen, 1972; simulated by Brandt et al, 1993) multiple choice experiments with chromatically filtered illumination, where color constancy holds and even where color constancy fails (Brandt et al, 1989); 6) experiments with neighboring color stimuli, where color shifts occurred by color induction (measurements and simulation by Dittrich, 1992). Thus both color induction and color constancy is explained in bees as being exclusively due to adaptation in the photoreceptors.

Electrophysiology: 7) the form of the response/log (I)-functions of tonic color opponent coding neurons (measurements by Kien and Menzel, 1977a; Hertel, 1980; simulations by Backhaus, 1991); 8) spectral sensitivity-functions of tonic color opponent coding neurons (measurements by Kien and Menzel, 1977b; spectral sensitivity functions derived in Menzel and Backhaus, 1989; simulations by Backhaus, 1991; see fig 5).

The close fit of observation to theory implicity confirms that: 1) the bee does not use a brightness system in color training experiments; 2) the MDS scale values are actually coded in 2 classes of neurons in the bee brain; 3 ) the photoreceptors show about half of the maximum response when exposed to an adapting light; 4) the ratios of the receptors' range of sensitivities $R$ are identical for dark adaptation and for adaptation to daylight (Backhaus, 1992); 5) in the case of adaptation to achromatic light, the range of sensitivities $R$ adapt independently of each other; 6 ) transduction in the photoreceptors is nonlinear; 7) on the other hand, color opponent coding is linear; 8) the perceptual color difference can be derived via the city-block metric from the excitations of the 2 types of color opponent coding neurons; 9) color similarity judgments in triadic experiments are performed by a comparison (subtraction) of the 2 color differences between the training stimulus and the alternatives; 10 ) the judgment values are weighted by an experiment- typedependent factor $F ; 11)$ the fluctuations in the judgment values are constant, ie Thurstone's (1927) law of comparative judgment, case $V$ holds; 12 ) the choice process is instantaneous; 13) the choice percentages can be derived from the weighted judgment values by $z$-transformation.

\section{COLOR MEMORIES}

As mentioned in the introduction, honeybees learn the color of the corolla of the currently visited flower species which enables flower constancy during foraging. Likewise, in color similarity experiments in which the training stimulus is not present in the tests, the information on the training color stimuli must be stored in memory for the determination of the color differences that are most important for the choice behavior (see above). As demonstrated, the color theory for the honeybee describes the results of this type of experiment very 
well. It is even possible to derive from this theory information on the organization of the color memory in the bee: 1) since no information on the intensity of the color stimuli is used in the choice behavior (see above), it appears very unlikely that the 3 excitation values of the photoreceptors will be stored in 3 independent memories. Since the photoreceptors provide information only on the intensity of the light stimuli, color information would have to be calculated via opponent color coding neurons before each comparison, which would be very uneconomic with respect to the number of neuronal circuits needed; 2) on the other hand, the information on the trained color cannot be stored as only one value. This is because the separate information of the 2 scale values $A$ and $B$ would be lost in this case and both the scale values are always needed for the determination of the color difference $d$ between 2 stimuli $S$ (see eq [3]). Thus it appears to be most likely that the information on a learned color, namely the 2 excitation values $A$ and $B$, is stored separately in 2 independent memories $\left(A_{1}\right.$ and $\left.B_{1}\right)$. These 2 memories have to be associated with each other in order to allow recall of the 2 values that belong to a specific stimulus. This type of memory organization allows straightforward determination of the color differences $d_{12}$ and $d_{13}$ between the learned color $\left(A_{1}\right.$ and $\left.B_{1}\right)$ and eg 2 alternative colors $\left(A_{2}, A_{3}\right.$ and $B_{2}, B_{3}$ ) (see fig 3 ).

\section{NEURONAL INTERPRETATION OF THE COLOR THEORY}

The color theory (eq [1-14]) for the honeybee allows a complete neuronal interpretation (fig 3 ) by a small number of neurons with simple (linear) properties, not only for the parts which were derived mainly from physiology (PR and COC models) but also for the psychophysical parts (MDS model).

\section{Neuronal interpretation of the city-block-metric}

The absolute values in the differences of the excitations $A$ and $B$ cannot be determined by a single neuron. But 2 neurons with zero resting frequency can easily derive this measure. These neurons code exclusively positive differences of the synaptical input. This is because neurons with zero resting frequency can only respond by rising $(>0)$ and not with lowering their spike frequency. The individual $(>0)$ neurons of such a pair appear to have exchanged excitatory and inhibitory synapses (fig 3). The sum of their respective outputs provides the absolute differences in the excitation values $A$ and $B$. This sum is provided by the judgment-value-neuron ${ }_{k} d_{i j}$ which thus realizes the city-block metric.

\section{The neuronal interpretation of the judgment values}

In the triadic color similarity experiments (see above), the judgement value neuron ${ }_{k} \mathrm{~d}_{i j}$ must get inhibitory input from additional $(>0)$-neurons, that provide the information on the color difference from the training color stimulus to the second alternative. The difference between the 2 color differences is performed via inhibitory and excitatory input from the $(>0)$-neurons. Since the judgment values can be either positive or negative, this neuron must possess a resting frequency comparable to that of the color opponent coding neurons.

\section{Neuronal fluctuations and the decision process}

The judgment process in triadic experiments (see above) implicite in the MDSmodel (Thurstone's (1927) law of compara- 
tive judgment, case V; Torgerson, 1958) can be described as follows: the 2 color differences, between the trained stimulus and the 2 alternatives, show fluctuations which are statistically independent of each other, and are described by Gaussian functions with equal standard deviations. The difference between 2 color differences that is coded in the judgment value neuron shows fluctuations that are also Gaussiandistributed with a constant SD. The latter fluctuations might be caused by the constant fluctuations from the $(>0)$-neurons, might be due to the intrinsic fluctuations of the judgment value neuron itself, or caused by a combination of both. The decision process is instantaneous, ie the stimuli are chosen according to the actual sign of the weighted judgment value at the moment of decision. If this value is > zero, 1 of the 2 alternatives is chosen, if this value is $<0$, the other alternative is chosen (see fig 3 ). The decision process is indeed well described by the simple $z$-transformation (see above). From all this it follows that the fluctuations at least in the judgment value neuron $\left({ }_{k} d_{i j}\right)$, and also in the $(>0)$-neurons if their contribution is significant, must be independent of their actual excitations. This is only possible if the intrinsic fluctuations in these neurons are much greater than the fluctuations in previous neurons and the photoreceptors. This conclusion is in agreement with the earlier finding of the author that the SD of the fluctuations determined for the choice behavior of the bee is ca 39-fold larger than the SD of the fluctuations determined for photoreceptors (Backhaus and Menzel, 1987).

\section{CONTRIBUTIONS OF OTHER SYSTEMS TO THE CHOICE BEHAVIOR}

The ouput of the judgment value neuron is weighted by a factor $F$ in the choice behavior. In mixed contexts, in which the choice behavior is not exclusively related to color vision, other perceptual systems may contribute appropriately weighted to the choice behavior via a behavioral combination rule. Independent perceptual systems can be investigated separately from each other. Or both systems can be stimulated simultaneously by changing both parameters of the stimuli (eg size and intensity) in the experiments. From the results of such experiments, the behavioral combination rule can be derived directly.

\section{Metrics as behavioral combination rule}

Ronacher (1979) in his experiments with honeybees varied the size and the total reflectance of grey stimuli, and obtained a city-block metric as the behavioral combination rule. This behavioral metric combines the outputs of 2 independent perceptual systems coding separately for size and brightness. Thus this metric has to be carefully distinguished from the perceptual metric determined for the 2-dimensional color space of the honeybee determined by the author (see above). The 2 perceptual color dimensions are not separable from each other, as is obvious from the BezoldBrücke effect (fig 6).

\section{Pseudometrics as a behavioral combination rule}

The behavioral combination rule must not necessarily possess the metric form. In mixed contexts, 1 stimulus (eg monochromatic light, $\lambda_{1}$ ) can be paired during conditioning for example with an aversive stimulus (eg vibration) and another stimulus (eg monochromatic light, $\lambda_{2}$ ) can be paired with a reward (no vibration). In this case, the stimuli can be chosen so that the effects of both may cancel each other out. 
Since one of the stimuli is attractive and the other causes aversive behavior in this case, the subjective differences in the 2 stimuli do not add in the choice behavior, but also contribute differences with a negative sign. The combination rule is called a pseudo-metric in this case, because the metric axiom of additivity is not fulfilled. Such a mixed context was used in the experiments of Hernandez de Salomon and Spatz (1983) who measured wavelength discrimination in the fruitly. If the concept of perceptual spaces holds for the color vision system of the fruitfly, one would expect the overall choice behavior to follow a pseudometric. Similar conditions are expected for the honeybee in mixed contexts in which, for example, color vision and photoaxis are combined.

\section{Logical relations as a behavioral combination rule}

In addition to the experiments mentioned above (fig 6), Menzel performed further experiments (1981, his fig 2) with monochromatic light of $533 \mathrm{~nm}$ in which the individual bee ( 3 bees in total) was trained to dark instead of to white light. For intensities above the absolute threshold of the photoreceptors, the choice percentages measured in the dark experiments are very close to those measured in the white experiments shown in figure $6 a$. In the white experiments, the bee showed the same response as to the trained bright white light, to an intensity of the $533 \mathrm{~nm}$ light just above the absolute threshold of the photoreceptors. These results are expected from the color theory, because the color space of the bee is 2-dimensional, and thus the bee cannot distinguish between dark and white light in ordinary color training experiments (see above). But at very low light intensities, below the absolute threshold of the photoreceptors, the meas- ured choice percentages show a great difference. In the dark experiments, the bee turned as expected to the side for achromatic light when the intensity of the 533$\mathrm{nm}$ light was below the absolute threshold. But in the white experiments the bee walked randomly (50\%:50\%) in this case (see fig 6a). The bee obviously used, in addition to color vision, a perceptual system which allows the bee to distinguish dark from lights which are achromatic for the color coding system. Obviously, this additional perceptual system does not contribute to the total subjective difference. Otherwise the predictions from the color theory would not hold as precisely as they do for intensities above the absolute threshold. Thus the information from the additional system must be logically related to the color choice behavior of the bee.

We suspect the additional system to be a form vision system. In the white experiments, the bee was trained to bright white and 533-nm light, and was never rewarded when the T-maze was dark. So the bee might have learned the rectangular form of the stimulus at the decision point to indicate that the food sources in the experimental setup provide a reward. Thus the bee chooses the sides of the T-maze according to the chromaticness of the light at the decision point, only if the light is sufficiently intense so that the form of the light is visible to the bee. If the form is not visible because the light intensity is too low, the bee does not care about chromaticness at all and thus walks randomly in this case. In the dark experiments, the form of the light at the decision point had no special meaning. The bee was trained to 533$\mathrm{nm}$ light of a rectangular form and to achromatic dark which had no bounds because the rest of the T-maze was also dark. Thus information from the form vision system had no special meaning to the bee in these experiments and thus had no influence on the choice behavior. 
From these results and further theoretical considerations, it is hypothesized that the behavioral combination rule according to which information from different perceptual systems is combined in the choice behavior of honeybees and other insects is a metric, a pseudometric or a logical relation. These relations can now be best studied in bees, because the theory of color vision and color choice behavior describes and already explains a major part of the total choice behavior in experiments with stimuli which affect the color vision system and other perceptual systems simultaneously. The effects of the other systems on the choice behavior can be studied directly from the deviations of the measured choice percentages from the predictions for pure color vision.

\section{OUTLOOK}

The author's color theory presented here describes and explains the color vision and the color choice behavior of the honeybee with high precision. The color theory is physiologically adequate, in that it explains not only the results obtained under artificial experimental conditions (see above) but also color vision during natural foraging on flowers. Although color vision and color choice behavior of the bee is mostly accounted for by the color theory, some topics remain to be investigated, ie: 1) adaptation: the color theory assumes independent adaptation of the 3 photoreceptor types as in the case for adaptation to achromatic lights (see above). For monochromatic adapting light, the adaptation mechanisms in the photoreceptors in behavioral color induction experiments turned out to be slightly coupled (Dittrich, 1992). Although monochromatic lights do not occur in the natural environment of the bee, the results of these experiments commend more specific investigations of the several adaptation processes, which are known to be due to eye optics as well as to the transduction process in the photoreceptors of the compound eye of the bee (Stavenga, 1979); 2) the color theory describes color vision of the bee exclusively for steady states. As shown above, this is indeed sufficient to explain ordinary color vision under experimental as well as under natural conditions. Nevertheless, for a complete physiological understanding of the neuronal color coding, it is necessary to extend the color theory by measuring and modeling the temporal properties of the photoreceptors and interneurons; 3) the differences in learning speed of monochromatic lights, as determined in behavioral experiments by Menzel (1967), remain to be explained by the color theory; 4) the theory does not assume anything about the existence of color sensations in bees. From this it cannot be concluded that color sensations do not occur in the bee. The first results of double training experiments, in which 2 color stimuli were trained simultaneously (Backhaus and Kratzsch, 1993), clearly demonstrate that the bee is able to perform color similarity judgments different from the judgment type described above. Thus, these results cannot be explained by the color theory. Rather, the results support the idea that bees have color sensations composed of unique colors (Backhaus, 1988b, 1991, 1992) just as in humans (see above). Thus both theoretical and empirical investigations of the color vision system of the honeybee will be continued.

\section{ACKNOWLEDGMENTS}

I would like to thank M Giurfa and anonymous referees for helpful comments on the manuscript, $P$ Maher for proof-reading of the English text, and A Klawitter for photo-technical assistance. 
Résumé - Vision des couleurs et comportement de choix des couleurs chez l'abeille, Apis mellifera L. La théorie des couleurs développée par l'auteur pour l'abeille décrit très bien la vision et le comportement de choix des couleurs. La théorie consiste en 5 modèles qui interagissent : 1) le modèle physiologique (PR) des photorécepteurs. 2) le modèle physiologique de codage opposé des couleurs $(\mathrm{COC})$. Celui-ci décrit le codage de la chromaticité (aspect bidimensionnel de la couleur qui est différent de la brillance) par 2 types de neurones codant en opposé linéairement. Un système de codage de la brillance n'est pas nécessaire parce que l'abeille ignore les différences d'intensité dans les expériences de dressage à la couleur. L'espace coloré subjectif de l'abeille est bidimensionnel, comme le montre l'analyse multidimensionnelle des pourcentages de choix des couleurs. 3) Le modèle psychophysique (MDS) de la perception des couleurs, qui décrit l'espace coloré. 4) Le modèle psychophysique (MDS) des jugements de similarité des couleurs. 5) Le modèle du comportement de choix des couleurs (CCB). La théorie des couleurs chez l'abeille a subi avec succès tous les tests critiques de comportement et d'électrophysiologie faits jusqu'à présent. Puisque la théorie est correcte du point de vue physiologique, elle explique la vision des couleurs chez l'abeille dans des dispositifs expérimentaux artificiels aussi bien que dans l'environnement naturel au cours des vols de butinage. La théorie permet une interprétation neuronale complète, y compris de la partie psychophysique, par des neurones aux propriétés simples. La mémoire des couleurs comprend probablement 2 parties indépendantes. Chaque couleur apprise est vraisemblablement stockée sous la forme des 2 valeurs d'excitation des 2 neurones codant en opposé les couleurs. De plus, la théorie des couleurs s'est montrée utile pour com- prendre les résultats des expériences dans lesquelles la vision des couleurs était stimulée simultanément avec d'autres modalités (par exemple, la vision des formes). L'hypothèse selon laquelle l'information concernant les différents stimuli est traitée séparément décrit bien les systèmes individuels de perception. L'information fournie par les systèmes individuels de perception est combinée, dans le comportement de décision, selon les règles des combinaisons comportementales (relation métrique, pseudo-métrique ou logique).

\section{vision des couleurs / comportement de choix / perception / psychophysique / électrophysiologie}

\section{Zusammenfassung - Farbensehen und} Farbwahlverhalten der Honigbiene, Apis mellifera L. Das Farbensehen und das Farbwahlverhalten der Honigbiene wird sehr genau durch die vom Author entwickelte Farbtheorie für die Honigbiene beschrieben. Die Theorie besteht aus fünf zusammenwirkenden Modellen: 1) Dem physiologischen (PR) Model der Photorezeptoren; 2) dem physiologischen gegenfarbenkodierenden (COC) Modell. Dieses Modell beschreibt die Farbart (den zweidimensionalen Aspekt einer Farbe, der von der Helligkeit verschieden ist) durch zwei linear gegenfarbenkodierende Neu-ronentypen. Ein helligkeitskodierendes System wird nicht benötigt, weil die Bienen Intensitätsunterschiede in Farbdressurexperimenten ignoriert. Der subjektive Farbraum der Honigbiene ist zweidimensional, wie die multidimensionale Skalierungsanalyse (MDS) von Farbwahlprozenten zeigte. Ferner 3) aus dem psychophysischen (MDS) Modell der Farbwahrnehmung, das den Farbraum beschreibt; 4) aus dem psychophysischen Model des Farbähnlichkeitsurteils und 5) aus dem (CCB) Modell des Farbwahlverhaltens. Die Farbtheorie für die Ho- 
nigbiene hat bisland alle kritischen verhaltensanalytischen und elektrophysiologischen Tests bestanden. Da die Theorie physiologisch adäquat ist, beschreibt sie das Farbensehen der Biene in künstlichen experimentellen Apparaturen sowie während der Sammelflüge in natürlicher Umgebung. Die Theorie erlaubt eine vollständige neuronale Interpretation, auch des psychophysischen Teils, durch Neuronen mit einfachen Eigenschaften. Das Gedächtnis der Biene für Farben dürfte aus zwei unabhängigen Teilen bestehen. Jede gelernte Farbe wird wahrscheinlich in Form der Erregungs-werte der zwei gegenfarbkodierenden Neuronen gespeichert. Überdies stellte sich die Farbtheorie sehr als nützlich heraus, für das Verständnis der Ergebnisse von Experimenten, in denen das Farbensehen gleichzeitig mit anderen Modalitäten (zB Formensehen) stimuliert wird. Die einzelnen Wahrnehmungssysteme werden bestens unter der Voraussetzung beschrieben, daß sie die Information über Reinzunterschiede unabhängig voneinander verarbeiten. Die von den einzelnen Wahrnehmungssysteme zur Verfügung stehende Information wird im Entscheidungsverhalten gemäß VerhaltensKombinationsregeln (Metrik, Pseudometrik oder logische Relation) verrechnet.

\section{Farbensehen / Wahlverhalten / Wahr- nehmung / Elektrophysiologie / Psycho- physik}

\section{REFERENCES}

Ahrens HJ (1974) Multimensionale Skalierung. Methodik, Theorie und empirische Gültigkeit mit Anwendungen aus der differentiellen Psychologie und Sozialpsychologie. Beltz Verlag, Weiheim

Autrum H, Zwehl V von (1964) Die spektrale Empfindlichkeit einzelner Sehzellen des Bienenauges. $Z$ Vgl Physiol 48, 357-384
Backhaus W (1987) Color vision in bees: similarity measures and metric scales of the perceptual space. Dissertation, Freie Universität Berlin. Mikroedition, ISBN 3-89349-650-5. Verlag der Deutschen Hochschulschriften, Egelsbach (1993)

Backhaus W (1988a) Color difference and color opponency in bees. In: Sense Organs. Interfaces between Environment and Behaviour. In: Proc 16th Göttingen Neurobiol Conf (Elsner N, Barth FG, eds) Thieme, Stuttgart, 219

Backhaus W (1988b) Opponent color coding and color perception in bees. In: Anais da XVIII Reuniao Anual de Psicologia (das Gracas de Souza et al, eds) Sociedade de Psichologia, Ribeirao Preto, 123-126 (In: Backhaus $W$ (1987) Color vision in honeybees and other insects. Habilitation thesis, Freie Universität Berlin, 1992; Mikroedition, ISBN 3-89349-648-3. Verlag der Deutschen Hochschulschritten, Egelsbach (1993))

Backhaus W (1991) Color opponent coding in the visual system of the honeybee. Vision Res 31, 1381-1397

Backhaus W (1992) The Bezold-Brücke effect in the color vision system of the honeybee. Vision Res 32, 1425-1431

Backhaus W, Kratzsch D (1993) Unique-colors in color vision of the honeybee? In: GeneBrain-Behavior. Proc 21st Göttingen Neurobiol Conf (Elsner $\mathrm{N}$, Heisenberg $\mathrm{M}$, eds) Thieme, Stuttgart 39, 830

Backhaus W, Menzel R (1984) Multidimensional scaling of the color space of honeybees (Bestimmung der Farbwahrmehmungskomponenten bei Bienen durch Multidimensionale Skalierung). Verh Dtsch Zool Ges 77. 230

Backhaus W, Menzel R (1987) Color distance derived from a receptor model for color vision in the honeybee. Biol Cybernet 55, 321-331

Backhaus W, Menzel R, Kreiß| S (1987) Multidimensional scaling of color similarity in bees. Biol Cybern 56, 293-304

Brandt R, Backhaus W, Dittrich M, Janetzki C, Menzel R (1989) Colour vision in bees: opponent coding and choice behavior. In: Dynamics and Plasticity in Neuronal Systems. Proc 17th Göttingen Neurobiol Conf (Elsner N, Singer W, eds) Thieme, Stuttgart, 100

Brandt R, Backhaus W, Dittrich M, Menzel R (1993) Simulation of threshold spectral sensi- 
tivity according to the color theory for the honeybee. In: Gene - Brain - Behavior. Proc 21st Göttingen Neurobiol Conf (Elsner N, Heisenberg M, eds) Thieme, Stuttgart, 374

Daumer K (1956) Reizmetrische Untersuchungen des Farbensehens der Bienen. $Z$ Vgl Physiol 38, 413-478

Dittrich M (1992) Vision in the honeybee: cotor induction. Dissertation, Freie Universität Berlin

Dittrich M, Backhaus W (1991) Frequenting times for color stimuli agree with predictions of the colour theory for the honeybee. $I n$ : Synapse-Transmission Modulation. Proc 19th Göttingen Neurobiol Conf (Elsner N, Penzlin H, eds) Thieme, Stuttgart, 561

Frisch $K$ von (1914) Der Farbensinn und Formensinn der Biene. Jb Abt Allg Zool Physiol 37, 1-238

Gohlke P, ed (1951-1961) Aristoteles. Die Lehrschriften, 8.1 Tierkunde. Schoeningh, Paderborn

Guilford JP (1937) Scale values derived from the method of choices. Psychometrika 2, 139-150

Helversen O von (1972) Zur spektralen Unterschiedsempfindlichkeit der Honigbiene. J Comp Physiol A, 80, 439-472

Henderson ST (1970) Daylight and its Spectrum. Hilger, London

Hering E (1905) Grundzüge einer Theorie vom Lichtsinn. Leipzig Engelmann (Outlines of a Theory of the Light Sense) (Hurvich LM, Jameson D, transl) Harvard Univ Press, Cambridge, MA (1964)

Hernandez de Salomon C, Spatz HC (1983) Colour vision in Drosophila melanogaster: wavelength discrimination. $J$ Comp Physiol $150,31-37$

Hertel H (1980) Chromatic properties of identified neurons in the optic lobes of the bee. $J$ Comp Physiol 137, 215-231

Hertel H, Maronde U (1987) Processing of visual information in the honeybee brain. In: Neurobiology and Behavior of Honeybees (Menzel R, Mercer A, eds) Springer, Berlin, 141157

Kien J, Menzel R (1977a) Chromatic properties of neurons in the optic lobes of the bee. I. Broad band neurons. J Comp Physiol A 113, 17-34
Kien J, Menzel R (1977b) Chromatic properties of neurons in the optic lobes of the bee. II. Narrow band colour opponent neurons. J Comp Physiol A, 113, 35-53

Kruskal JB (1964a) Multidimensional scaling by optimizing goodness of fit to a nonmetric hypothesis. Psychometrika 29, 1-29

Kruskal JB (1964b) Nonmetric multidimensional scaling: a numerical method. Psychometrika 29, 115-131

Labhart T (1974) Behavioral analysis of light intensity discrimination and spectral sensitivity in the honeybee, Apis mellifera. J Comp Physiol 95, 203-216

Laughlin SB (1981) Neural principles in the peripheral visual systems of invertebrates. In: Handbook of Sensory Physiology (Autrum H, ed) Springer, Berlin, vol VII/6B, 133-280

Lipetz LE (1971) The relation of physiological and psychophysical aspect of sensory intensity. In: Handbook of Sensory Physiology (Loewenstein WR, ed) Springer, Berlin, vol I, 191-225

Menzel R (1967) Untersuchungen zum Erlernen von Spektralfarben durch die Honigbiene, Apis mellifica. Z Vgl Physiol 56, 22-62

Menzel R (1974) Spectral sensitivity of monopolar cells in the bee lamina. J Comp Physiol 93, 337-346

Menzel R (1981) Achromatic vision in the honeybee at low intensities. J Comp Physiol A, 141, 389-393

Menzel R, Backhaus W (1989) Color vision in honeybees: phenomena and physiological mechanisms. In: Facets of Vision (Stavenga DG, Hardie RC, eds) Springer, Berlin, 281297

Menzel R, Backhaus W (1991) Colour vision in insects. In: Vision and Visual Dysfunction (Cronly-Dillon, ed) vol 6; The Perception of Colour (Gouras P, ed) Macmillan, London, chap 14, 262-293

Menzel R, Greggers U (1985) Natural phototaxis and its relationship to colour vision in honeybees. J Comp Physiol 157, 311-321

Menzel R, Ventura DF, Hertel $H$, de Souza JM, Greggers U (1986) Spectral sensitivity of photoreceptors in insect compound eyes: comparison of species and methods. J Comp Physiol A, 158, 165-177 
Ronacher B (1979) Äquivalenz zwischen Größen- und Helligkeitsunterschieden im Rahmen der visuellen Wahrnehmung der Honigbiene. Biol Cybern 32, 63-75

Sachs L (1976) Statistische Methoden. Springer, Berlin

Sixtl F (1982) Meßmethoden der Psychologie. Theoretische Grundlagen und Probleme, 2. überarbeitete und enweiterte Auflage. Beltz Verlag, Weinheim

Souza JM de, Hertel H, Ventura DF, Menzel R (1992) Response properties of stained monopolar cells in the honeybee lamina. J Comp Physiol A 170, 267-274
Stavenga DG (1979) Pseudopupils of compound eyes. In: Handbook of Sensory Physiology: Vision in Invertebrates (Autrum $\mathrm{H}$, ed) vol VII/6A, Springer, Berlin, 357-439

Thurstone LL (1927) A law of comparative judgment. Psychol Rev 34, 273-286

Torgerson WS (1958) Theory and Methods of Scaling. Wiley, New York

Wyszecki G, Stiles WS (1982) Color Science. Concepts and Methods, Quantitative Data and Formulae. Wiley, New York, 2nd ed

Zielinski R (1978) Erzeugung von Zufallszahlen, Programmierung und Test auf Digitalrechnern. Deutsch Verlag, Frankfurt am Main 